\title{
Commentary: Take your time but quickly! Impact of time to surgery in early esophageal cancer
}

\author{
Monisha Sudarshan, MD, MPH, and Siva Raja, MD, PhD
}

\footnotetext{
From the Department of Thoracic and Cardiovascular Surgery, Heart and Vascular Institute, Cleveland Clinic, Cleveland, Ohio.

Disclosures: Authors have nothing to disclose with regard to commercial support.

Received for publication Oct 7, 2019; revisions received Oct 7, 2019; accepted for publication Oct 7, 2019; available ahead of print Feb 5, 2020.

Address for reprints: Siva Raja, MD, PhD, Heart and Vascular Institute, Cleveland Clinic Foundation, 9500 Euclid Ave J4-1, Cleveland, OH 44195 (E-mail: rajas@ccf.org).

J Thorac Cardiovasc Surg 2020;159:1636-7

$0022-5223 / \$ 36.00$

Copyright $(2019$ by The American Association for Thoracic Surgery

https://doi.org/10.1016/j.jtcvs.2019.10.023
}

Time is pivotal for the cancer patient. Shorter time to treatment possibly serves to improve oncologic outcomes and survival. ${ }^{1}$ In the complex world of esophageal surgery, balancing this interval with taking the time for appropriate staging, workup of comorbidities, and optimization of surgical candidacy remains equally crucial. Avoidable delays to treatment include insurance-related issues, access to facilities, and slow institutional processes. ${ }^{2}$ We all recognize that a delay is unfavorable, but at what point is it associated with measurable morbidity? These answers can help form patient expectations, quality control targets, revise institutional processes, and guide policies.

Raman and colleagues ${ }^{3}$ use the National Cancer Database (NCDB) to investigate how time to upfront surgery can impact mortality and positive margins for T1NOM0 esophageal cancer. Time to surgery was analyzed in quartiles and as a continuous variable. Division in quartiles did not yield statistically significant difference in outcome, but using restricted cubic spline, the group showed a statistical difference with a small effect size. Mortality for time to surgery past 100 days was associated with a hazard ratio of 1.00 and $95 \%$ confidence interval of $1.00-1.01, P=.003$. Similarly, the group reported positive margins associated with time to surgery $>100$ days as and odds ratio, 1.01 (95\% confidence interval, 1.00-1.02, $P=.004$ ). The small effect size limits the clinical impact of these results.

The findings become contentious, since a delay to surgery harbors several confounders that could not be accounted for in this study. In early cancer, most patients will undergo endoscopic resection for diagnosis and treatment. Positive margins from such procedures now convert this patient to a surgical candidate, increasing days to surgical treatment from diagnosis, and have the associated poorer outcomes from a positive endoscopic procedure. Unfortunately, such granular data are not present in the NCDB and could not be adjusted for in the analysis. The need for pre-habilitation in the form of nutrition or cardiorespiratory optimization also leads to a justifiable deferral for surgery

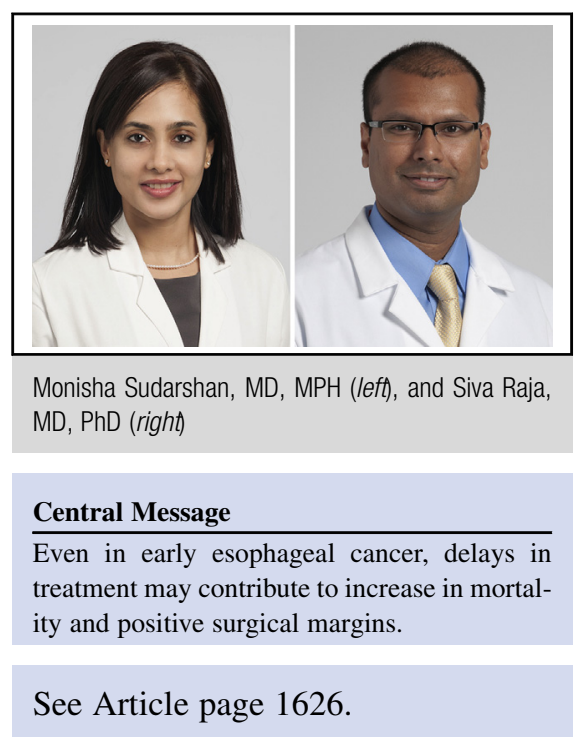

for a population whose outcomes are compromised due to comorbidities rather than time to treatment. But once again, it is impossible to recognize the contribution of this cohort within an administrative database.

In an era in which there are increasing wait times to cancer surgery ${ }^{4}$ and the access and navigation of health care systems are getting more complex, ${ }^{5}$ we need to track and minimize unnecessary and preventable delays. Khorana and colleagues ${ }^{6}$ have also used the NCDB to demonstrate that increasing time to curative intervention is associated with an absolute increased risk of mortality of $1.2 \%$ to $3.2 \%$ per week in some solid-organ cancers. ${ }^{6}$ On the contrary, for early pancreatic cancer, shorter time periods to upfront surgery have been associated with a decrease in survival.

So have Raman and colleagues found a smoking gun in terms of negative outcomes from delaying treatment in early esophageal cancer? Not yet. Intuitively, most would say that even 100 days (as examined in this study) is too long and perhaps the 30-day target at many institutions may be too short. Any reasonable goal has to also consider patient anxiety, where they often believe every day counts. The work here by Raman and colleagues does start the conversation about having a balance between the time it takes to ensure the necessary preoperative workup/optimization including the use of endoscopic therapy (diagnostic and therapeutic) and moving forward quickly when it comes to minimizing preventable delays. 


\section{References}

1. Samson P, Patel A, Garrett T, Crabtree T, Kreisel D, Krupnick AS, et al. Effects of delayed surgical resection on short-term and long-term outcomes in clinical stage I non-small cell lung cancer. Ann Thorac Surg. 2015;99: 1906-13.

2. Kirkwood MK, Hanley A, Bruinooge SS, Garrett-Mayer E, Levit LA, Schenkel C, et al. The state of oncology practice in America, 2018: results of the ASCO practice census survey. J Oncol Pract. 2018;14:e412-20.

3. Raman V, Jawitz O, Voigt S, Chi-Fu Y, Wang H, Harpole D, et al. Effect of time to surgery on outcomes in stage I esophageal cancer. J Thorac Cardiovasc Surg. 2020;159:1626-35.e1.

4. Bilimoria KY, Ko CY, Tomlinson JS, Stewart AK, Talamonti MS, Hynes DL, et al. Wait times for cancer surgery in the United States: trends and predictors of delays. Ann Surg. 2011;253:779-85.

5. Lin NU, Bichkoff $\mathrm{H}$, Hassett MJ. Increasing burden of prior authorizations in the delivery of oncology care in the United States. J Oncol Pract. 2018;14:525-8.

6. Khorana AA, Tullio K, Elson P, Pennell NA, Grobmyer SR, Kalady MF, et al. Time to initial cancer treatment in the United States and association with survival over time: an observational study. PLoS One. 2019;14:e0213209.

7. Swords DS, Zhang C, Presson AP, Firpo MA, Mulvihill SJ, Scaife C. Association of time-to-surgery with outcomes in clinical stage I-II pancreatic adenocarcinoma treated with upfront surgery. Surgery. 2018;163:753-60. 